\title{
Critical loads of atmospheric nitrogen deposition for sensitive high-elevation ecosystems in the western United States
}

\author{
L. NANUS ${ }^{1 *}$, D.W. CLOW ${ }^{2}$, J.E. SAROS ${ }^{3}$, J.A.
} MCMURRAY $^{4}$, J.O. SICKMAN ${ }^{5}$

${ }^{1}$ San Francisco State University, San Francisco, California, USA (* correspondence: lnanus@sfsu.edu)

${ }^{2}$ United States Geological Survey, Denver, Colorado, USA (dwclow@usgs.gov)

${ }^{3}$ University of Maine, Orono, Maine, USA (jasmine.saros@maine.edu)

${ }^{4}$ United States Forest Service, Jackson, Wyoming, USA (jamcmurray@fs.fed.us)

${ }^{5}$ University of California Riverside, Riverside, California, USA (james.sickman@ucr.edu)

High-elevation ecosystems in the western United States (US) are impacted by current and historic atmospheric nitrogen $(\mathrm{N})$ deposition associated with local and regional air pollution. Documented effects include elevated surface water nitrate concentrations, increased algal productivity, and changes in diatom species assemblages. A predictive framework was developed for sensitive high-elevation basins in the Rocky Mountains and Sierra Nevada at multiple spatial scales. Critical loads of $\mathrm{N}$ deposition for nutrient enrichment of aquatic ecosystems were quantified and mapped using a geostatistical approach, with modeled $\mathrm{N}$ deposition, topography, vegetation, geology, and climate as potential explanatory variables. Rather than relying on a single predictive model, multiple predictive models were developed using various combinations of explanatory variables; this approach allowed for better quantification of uncertainty and more accurate identification of the aquatic ecosystems most sensitive to high atmospheric $\mathrm{N}$ deposition $\left(>3 \mathrm{~kg} \mathrm{~N} \mathrm{ha}^{-1} \mathrm{yr}^{-}\right.$ $\left.{ }^{1}\right)$. The lowest critical loads estimates $\left(<1.0+1 \mathrm{~kg} \mathrm{~N} \mathrm{ha}^{-1}\right.$ $\mathrm{yr}^{-1}$ ) occurred in high-elevation basins with steep slopes, sparse vegetation, and exposed bedrock and talus. Estimated critical load exceedances correspond with areas of high $\mathrm{N}$ deposition and vary spatially. Broad areas of the Rocky Mountains and Sierra Nevada may be impacted by excess N deposition, with greatest impact at high elevations. The approach presented here may be transferable to other remote and protected high-elevation ecosystems that are sensitive to adverse effects of pollutant loading in the US and around the world. 